\title{
El rol del licenciado en turismo en Argentina. Caso: Universidad Nacional de Mar del Plata
}

\author{
The roll the licenciado in tourism in Argentina. Case: National University of Mar \\ del Plata
}

Marta Mónica Asensio (ASENSIO, M. M.)*

\begin{abstract}
RESUMEN: El trabajo describe la evolución del Rol del Licenciado en Turismo egresado de la Universidad Nacional de Mar del Plata. Se divide en cinco etapas: Aprovisionamiento, Carreteo, Despegue, Travesía y Aterrizaje; indicativa cada una de la formación académica; mencionando el contexto económico, político, social y del mercado turístico donde ejerce su profesión el graduado. Se concluye con una propuesta del Rol que debe ejercer el Licenciado en Turismo ante los cambios de la disciplina en el mundo y en Argentina.

Palabras-clave: Licenciatura en Turismo - Universidad Nacional de Mar del PlataEjercicio de la Profesión.
\end{abstract}

ABSTRACT: The work describes the evolution of the Rol of the Graduate in Tourism egresado of the National University of Sea of the Silver. Divide in five stages: Aprovisionamiento, Carreteo, Despegue, Travesía and Landing; indicativa each one of the academic training; mentioning the economic context, political, social and of the market turístico where exerts his profession the graduated. Conclude with a proposal of the Rol that has to exert the Graduate in Tourism in front of the changes of the discipline in the world and in Argentina.

Keywords: Licenciado in Tourism - National University of Mar del Plata - exerts its profession.

\footnotetext{
* 1. Licenciada en turismo (Universidad Nacional de Mar del Plata /1976). 2. Perito en turismo. 3. Guía de turismo. 4. Experto en MERCOSUR. 5 Directora de la carrera licenciatura en turismo - (Universidad Nacional de Mar del Plata). Profesora Adjunta de la Cátedra: Organizaciones Turísticas II. Directora proyectos de Extensión de la Universidad Nacional de Mar del Plata. Integrante de la comisión directiva de la Asociación de Licenciados en Turismo de Mar del Plata.

Contacto: Asturias 1.230 M4. P1. D5. / 7600 Mar del Plata - Provincia de Buenos Aires - Argentina. Teléfono y fax: 054-223-479-4654 (particular). Facultad de Ciencias Económicas y Sociales: Teléfono: 054-223-474-9696 - Funes 3250 / 7600. Mar del Plata - Provincia de Buenos Aires - Argentina. E-mail: madrugada@copetel.com.ar
} 


\section{INTRODUCCIÓN}

En la República Argentina, en los últimos cinco años, aumentó la importancia del turismo y su impacto dentro de la economía del país. La comunidad lo reconoce como motor para impulsar el desarrollo de las economías regionales, generando fuentes de empleo a la vez que da a conocer los atractivos naturales y culturales del país sumado los distintos tipos de vida de las comunidades anfitrionas.

En el primer trimestre del año 2007 el turismo receptivo superó los 600.000 turistas ingresados al país, cifra récord en la serie trimestral y que confirma la tendencia en alza para esta variable, representando un $11 \%$ del movimiento turístico total registrado en un 15,5\%, correspondiéndole un $24 \%$ al turismo emisivo.

La balanza turística, en cambio registró una disminución del 3,5\%, impactada por el aumento del turismo emisivo. (INDEC, 2007, p. 1) ${ }^{1}$

Este escenario compromete a plantear nuevas responsabilidades y reflexiones a todos los actores de la escena turística: académicos, sector público, sector privado, licenciados en turismo y políticos en la gestión municipal, provincial y nacional.

El turista de hoy está informado, compara tarifas, calidad de servicios en los destinos priorizando el buen trato, la seguridad en lo referente a su persona y al cumplimiento de los servicios contratados. En consecuencia, los destinos turísticos tienen que iniciar un proceso de renovación, con innovación, profesionalizando al sector sin olvidar la sustentabilidad de la actividad, procurando optimizar la calidad del servicio, componente distintivo en un mercado competitivo y cambiante.

El Licenciado en Turismo es el profesional con carrera de grado formado en la Universidad Nacional de Mar del Plata - y en otras Unidades Académicas de Gestión Pública y/o Privada, con cuatro o cinco años de estudios - para planificar, gestionar, coordinar e impulsar todas las actividades propias del Turismo.

El objetivo del trabajo es demostrar la evolución de la Formación del Licenciado en Turismo en la Universidad Nacional de Mar del Plata y los motivos por los cuales es el profesional competente y apto para el ejercicio de la conducción y gestión del desarrollo turístico sustentable en el país participando en todas las organizaciones turísticas públicas, privadas o mixtas.

\footnotetext{
${ }^{1}$ Instituto Nacional de Estadísticas y Censo (INDEC), Argentina, 2007.
} 
Es un trabajo descriptivo, producto del análisis de la experiencia personal vivida desde el año 1969, como alumna, docente, graduada en la Licenciatura en Turismo, gestionando desde el año 2002 la carrera en cargo de Directora de Turismo de la Facultad de Ciencias Económicas y Sociales de la Universidad Nacional de Mar del Plata-.

Está dividido en cinco etapas. Cada una menciona el contexto social, económico, académico y del mercado turístico dónde licenciado en turismo se forma; arribando a conclusiones que fundamentan el Rol del Licenciado en Turismo en la Argentina. El objeto de estudio es el graduado de la Universidad Nacional de Mar del Plata. La problemática es similar en graduados de otras Unidades Académicas del país.

\title{
2 DESARROLLO
}

\begin{abstract}
El turismo, fenómeno de naturaleza compleja y concebido como conjunto de actividades diversas, ha constituido y constituye un factor de transformación y un componente estructural de nuestra sociedad. Su complejidad y diversidad se concretan en distintas manifestaciones (sociales, económicas, geográficas, políticas...) y por ello ha sido y es objeto de estudio por parte de diversas disciplinas científicas (economía, geografía, sociología, antropología, arquitectura y urbanismo...), que han abordado su problemática, y ha sido y es objeto de atención por parte de entidades, instituciones y organismos, tanto de carácter público como privado. (REBOLLO, 1997, p. 21)
\end{abstract}

Esta definición es del año 1997, pasaron 10 años, es la que expresa con claridad el fenómeno del turismo.

El turismo es un fenómeno internacional, de estructura compleja en continuos y rápidos cambios en lo social, tecnológico y político requiere formación de profesionales que sean el producto de la perfecta y equilibrada ecuación de los tres saberes que sustentan los planes de estudios en la formación de competencias: saber, saber hacer y ser para satisfacer las necesidades de una demanda cada vez más exigente, donde los Estados son concientes que es una actividad económica que genera una fuente de ingresos importante y en algunos casos la mayor.

Es en este contexto dónde el Licenciado en Turismo se forma con valores humanos, que accionará con sus actitudes para desarrollar su profesión. 
Los antecedentes de formación académica, se remontan a comienzos del siglo XX. Los países pioneros en incluir al turismo en la formación académica son en la década del 20 en Italia, Alemania y Reino Unido en la década del 30, y posteriormente Estados Unidos. Canadá, se incorporó más tarde siendo el creador de un centro mundial de Investigación y educación en turismo (Universidad de Calgary) con importante influencia en todo el mundo.

En Argentina los estudios en Turismo se originan a fines de la década del 60, respondiendo a necesidades del sector privado en los centros receptores de turismo tal es el caso de Mar del Plata., se dictaban cursos cortos solicitados por los hoteleros, siendo los docentes propietarios de alojamientos con predisposición a transmitir experiencias laborales.

El proceso evolutivo de la formación del licenciado en turismo no es ajeno a los requerimientos del mercado, influenciado por la situación política, económica y social.

Para facilitar la comprensión del trabajo se identifican cinco etapas denominadas: Aprovisionamiento, Carreteo, Despegue, Travesía y Aterrizaje, utilizando terminología del transporte aéreo, modalidad precursora del turismo internacional transcontinental. Cada una representa la trayectoria transitada por la Carrera Licenciatura en Turismo, desde su comienzo hasta la actualidad, en lo académico y por lógica consecuencia la inserción del graduado en el ejercicio de su profesión, dentro del contexto social, político y desde la percepción que tiene la comunidad de la profesión.

La etapa del “Aprovisionamiento": Comienza a fines de los años sesenta, abarcando la década del 70 .

Al futuro profesional en turismo se lo aprovisiona, formándolo con saberes de todas las disciplinas citadas en la definición anterior: geografía, historia, sociología derecho, contabilidad, economía. Se reconoce al turismo como un fenómeno social y económico, se intuye su futuro, existe el esfuerzo y voluntad por parte de la comunidad de formar profesionales que se adapten a las necesidades del núcleo receptor. El alumno adapta los conocimientos provenientes del estudio de bibliografía española o mexicana, recomendada en los programas de estudios por arquitectos, ingenieros, contadores, profesores de geografía y abogados que ejercieron la función docente en los inicios de la carrera - continuando en la actualidad en algunas cátedras- . La 
comunidad identifica a la profesión de Licenciado en Turismo con la de un guía memorista y un viajero constante, no comprendiendo la competencia profesional.

La ciudad de Mar del Plata es un centro receptivo con turismo social cautivo a causa de las inversiones en hotelería por parte de los gremios. Es el auge de la ciudad, del turismo masivo. Los servicios se prestan en organizaciones de origen familiar, donde sólo bastaba la hospitalidad del núcleo receptor, la buena gastronomía y el alojamiento. Los atractivos naturales y culturales, garantizaban el turismo estacional.

Ante el crecimiento espontáneo de la actividad el estado inicia los controles creando un marco regulatorio y así los requerimientos del mercado son otros, obligando a los prestadores a crear nuevos servicios a los ya existentes (alojamiento, transporte y gastronomía, comienzan a calificarse), es la etapa donde las empresas de origen familiar, envían a los más jóvenes a capacitarse.

En la década del 70 el estado incorpora a las Universidades de gestión pública en la enseñanza del turismo, antes lo hacían universidades privadas.

En la etapa del Aprovisionamiento los estudiantes avanzados, ingresan en la docencia universitaria adaptando los conocimientos adquiridos al objeto de estudio: El Turismo. Tímidamente lo hacen en los cargos docentes de ayudantes, y se detecta la necesidad de cambiar los planes de estudios.

Académicamente se caracteriza por ser la década que promovió tres planes de estudios. Los disparadores que los originaron fueron el proceso militar instalado en el gobierno y el concepto dominante que consideraba al turismo como una actividad económica. Resultante de este cuadro es el paso de una formación académica humanista a una economista.

De un plan con diseño curricular con títulos intermedios: Guía, Perito y Licenciado, con asignaturas básicas de distintas disciplinas, se cambia a un plan de estudios con título intermedio de Técnico, con asignaturas tradicionales adaptadas al turismo y trabajos prácticos de campo.

El Plan "B" es un Plan con diseño curricular organizado por asignaturas, con la incorporación de otras instancias: las prácticas profesionales, que permite alcanzar el dominio de destrezas y habilidades técnicas precisas en el ejercicio de la profesión.

Resumiendo: en esta etapa los primeros egresados son Licenciados aprovisionados de saber y hacer cosas. Les compete el SER como profesionales al que 
arriban por reflexión propia del análisis de todos los conocimientos, y de aprehender el significado del turismo, que comprende valores de responsabilidad, tolerancia, solidaridad y respeto.

Con este aprovisionamiento se dirigen a la segunda etapa, la del "Carreteo", necesaria para remontar vuelo.

Es la década del 80. A partir de los principios enumerados en Manila y la evolución tecnológica del transporte, se aceleran los procesos de transformación en el turismo, ingresando nuevas disciplinas constituyéndose en herramientas necesarias en la formación del profesional, el marketing, el concepto de desarrollo sustentable aplicado al turismo, sumado a las nuevas técnicas de gestión empresarial aplicadas a los servicios más el ingreso de los sistemas de reservas, conlleva a que las universidades modifiquen los planes de estudios.

En todos los servicios nace el concepto de control de calidad.

En la Universidad Nacional de Mar del Plata, se instala por toda esta década un plan de estudios con formación económica.

Los Licenciados en Turismo, comienzan a ocupar cargos de J.T.P., participan en agrupaciones con pares, se organizan debates y se estudia la problemática del turismo.

La comunidad reconoce la necesidad de profesionales en empresas de servicios y la imagen del licenciado se asocia con cargos gerenciales en hotelería y agencias de turismo, se reconoce a la actividad como un activador de la economía.

A partir de 1983, el gobierno democrático marca cambios en la participación social. Se incorpora la recreación como actividad necesaria para la satisfacción personal del hombre En este escenario democrático es donde los licenciados inician la lucha esperanzada en un ejercicio profesional reconocido por la comunidad y se toman fuerzas para iniciar el despegue.

La etapa del "Despegue", se inicia en la década del 90. El turismo y la recreación son abordados en su problemática, se forman grupos de indagación en el Centro de Investigaciones Turísticas de la Universidad Nacional de Mar del Plata.

Se modifica en el año 1993 el Plan de Estudios, se incorpora la recreación, la conservación de los recursos y como materias troncales todos los servicios turísticos, comercialización, investigación, con requisitos de idioma inglés y computación. 
El Plan de Estudios es confeccionado por Licenciados en Turismo, ejerciendo estos profesionales cargos docentes en las jerarquías de titulares, adjuntos y JTP.

Se crea la ALT (Asociación de licenciados en Turismo de Mar del Plata) y la comunidad reconoce, que ante los cambios surgidos en la demanda, la aparición de centros turísticos que compiten con la ciudad, un contexto social en continuo cambio, es necesario planificar la actividad turística para alcanzar un desarrollo sustentable preservando los recursos y utilizar estrategias de marketing para la gestión del turismo en todos sus ámbitos.

En Argentina, en 1995, la Ley de educación 24.195 incorpora al turismo como un contenido transversal en EGB.

Las editoriales publican libros para EGB con temas turísticos y actividades relacionadas e integradas en todas las áreas.

En ese mismo año la Ley de Educación Superior 24.521 en el Art. 40 establece que las Universidades les corresponden otorgar títulos de grado y postgrado.

En 1999 la continua evolución lleva a la OMT (Organización Mundial del Turismo) redactar el "Código Ético mundial para el Turismo". En este código se resaltan los valores del turismo, incluyendo el concepto de turismo responsable y sostenible, y convocando a la conciliación a la economía, ecología, medio ambiente y desarrollo; y apertura a los intercambios internacionales y protección de las identidades sociales y culturales.

Este código considera que:

Todos los agentes del desarrollo turístico,... entre ellos las asociaciones profesionales, ejercemos responsabilidades diferenciadas pero interdependientes en la valoración individual y social del turismo y que la definición de los derechos y deberes de cada uno contribuirá a lograr ese objetivo”. (CÓDIGO ÉTICO MUNDIAL PARA EL TURISMO, 1999, p. 3)

Comienzan a Multiplicarse los establecimientos terciarios privados que imparten enseñanza del Turismo.

La tecnología ingresa en todas las actividades turísticas convirtiéndose en una herramienta indispensable de trabajo. La sociedad reconoce en el turismo una fuente de ingreso.

En Mar del Plata se promociona este slogan: "El buen trato genera turismo y el turismo genera trabajo." 
Con un despegue donde el profesional en turismo tiene los saberes básicos adquiridos, sumados al saber hacer con el dominio de destrezas y habilidades más su actitud personal ( el ser) está preparado y tiene experiencia para iniciar la etapa de la travesía.

La etapa de la "Travesía” coincide con el comienzo del siglo XXI.

Avanzado en tres años, en Mar del Plata, la oferta educativa de carreras turísticas se incrementa a nivel terciario y universitario. En el caso de la Universidad Nacional de Mar del Plata, se intensifica la investigación con el Centro de Investigaciones Turísticas, se implementa la ampliación del Centro de Documentación de la Facultad con un área específica en Turismo, logrado gracias a la ayuda económica recibida de la Universidad de Islas Baleares, comenzando la Asociación de Licenciados en Turismo a intensificar su acción en la comunidad por intermedio de foros, mesas de debate jornadas y cursos en asociación con los centros de formación y se inserta en la comunidad estudiando la problemática del turismo.

En educación Polimodal, escuelas medias con orientación turística, solicitan para el dictado de las asignaturas a Licenciados en Turismo, para cubrir los cargos de horas institucionales. Los organismo Públicos de Turismo, a nivel municipal y provincial, inician proyectos en forma conjunta, con profesionales en turismo, universidades y alumnos.

Es en esta la etapa donde los Licenciados en Turismo se asocian creando colegios profesionales en dos provincias: Misiones y Río Negro.

La Asociación de Licenciados en Turismo tiene su representante en el Consejo Asesor del EMTUR, al igual que la Carrera Licenciatura en Turismo de las Universidades de Gestión Pública y Privada.

A partir del 8 de mayo del 2003, en el Primer Encuentro de Profesionales en Turismo realizado en la Ciudad Autónoma de Buenos Aires los Licenciados en Turismo fijan un objetivo común: asociarse y defender el campo profesional que le compete por el perfil de su formación.

Se eleva la autoestima de la profesión.

El 17 de diciembre de 2004 se sanciona la Ley Nacional de Turismo - Ley 25.997 y se reglamenta en 27 de setiembre de 2006.

En el artículo primero reza: 
Declárase de interés nacional al turismo como actividad socioeconómica, estratégica y esencial para el desarrollo del país. La actividad turística resulta prioritaria dentro de las políticas de Estado...." "Objeto. La presente ley tiene por objeto el fomento, el desarrollo, la promoción y la regulación de la actividad turística y del recurso turismo mediante la determinación de los mecanismos necesarios para la creación, conservación, protección y aprovechamiento de los recursos y atractivos turísticos nacionales, resguardando el desarrollo sostenible y sustentable y la optimización de la calidad, estableciendo los mecanismos de participación y concertación de los sectores público y privado en la actividad. (LEY 25.997, 2004, p. 2)

En el Anexo I nombra a las: Actividades comprendidas conforme a las clasificación internacional uniforme de las actividades turísticas de la Organización Mundial del Turismo”. (Ley 25.997, 2004, p. 2)

1. Actividades directamente vinculadas con el turismo.

1.1. Servicios de alojamiento

1.1.1. Servicios de alojamiento en camping y/o refugios de montaña.

1.1.2.Servicios de alojamiento en hoteles, hosterías, cabañas bungalow, aparts y residenciales similares, excepto por hora, que incluyen restaurante.

1.1.3.Servicios de alojamiento en hoteles, hosterías, cabañas bungalow, aparts y residenciales similares, excepto por hora, que no incluyen restaurante.

1.1.4. Servicios de hospedaje en estancias y albergues juveniles.

1.1.5. Servicios en apartamentos de tiempo compartido.

1.2. Agencias de Viajes.

1.2.1. Servicios de empresas de viajes y turismo.

1.2.2.Servicios de agencias de turismo y agencias de pasages.

\subsection{Transporte}

\subsubsection{Servicios de transporte aerocomercial.}

1.3.2. Servicios de alquiler de aeronaves con fines turísticos.

1.3.3. Servicios de excursiones en trenes especiales con fines turísticos.

1.3.4. Servicios de excursiones fluviales con fines turísticos.

1.3.5.Servicios de excursiones marítimas con fines turísticos.

1.3.6.Servicios de transporte automotor de pasajeros para el turismo.

1.3.7. Servicios de alquiler de equipos de transporte terrestre sin operación tripulación.

1.4.Servicios profesionales de Licenciados en Turismo, Técnicos en Turismo y Guías de Turismo 


\subsection{Otros servicios.}

1.5.1. Servicios de centros de esquí.

1.5.2. Servicios de pesca deportiva.

1.5.3 .Servicios de centros de turismo salud, turismo termal y/o similares.

1.5.4 .Servicios de centros de turismo aventura, ecoturismo o similares.

1.5.5. Servicios de otros centros de actividades vinculadas con el turismo.

1.5.6. Alquiler de bicicletas, motocicletas, equipos de esquí u otros artículos relacionados con el turismo.

1.5.7. Servicios de jardines botánicos, zoológicos y de parques nacionales.

1.5.8. Servicios de parques de diversiones, parques temáticos, entretenimientos, esparcimiento y ocio.

1.5.9. Servicio de explotación de playas y parques recreativos.

1.5.10. Servicios de museos y preservación de lugares y edificios históricos.

1.6. Servicios vinculados a la organización de ferias, congresos, convenciones y/o exposiciones.

1.6.1. Servicio de alquiler y explotación de inmuebles para ferias, congresos y/o convenciones.

1.6.2. Servicios empresariales vinculados con la organización de ferias, congresos y/o convenciones.

1.6.3. Servicios de alquiler de equipamiento para la realización de ferias, congresos y/o convenciones.

2. Actividades indirectamente vinculadas con el turismo.

2.1. Gastronomía

2.1.1. Servicios de cafés, bares y confiterías.

2.1.2. Servicios de restaurantes y cantinas.

2.1.3. Servicios de salones de baile y discotecas.

2.1.4. Servicios de restaurante y cantina con espectáculo.

2.2. Otros servicios.

2.2.1. Venta al por menor de artículos regionales de talabartería de cuero, plata, alpaca y similares.

2.2.2. Venta al por menor de artículos y artesanías regionales.

2.2.3. Venta de antigüedades (Anexo I, 2004, p. 36) 
En forma simultánea a la promulgación de la Ley de Turismo, en la Universidad Nacional de Mar del Plata, por OCA, n. 883 (Ordenanza de Consejo Académico de la Facultad de Ciencias Económicas y Sociales) se implementa el Plan de Estudios "E”, de la carrera Licenciatura en Turismo. La discusión de la implementación del Plan comenzó en el año 2003. Participaron en su diseño los tres claustros que integran la comunidad universitaria: docentes, graduados y alumnos, contando su aprobación con el consenso mayoritario.

El Perfil Profesional del graduado está formado para desarrollar su ejercicio profesional en las siguientes competencias:

Participar en:

Análisis e investigación conceptual y aplicada del turismo y la recreación en su carácter integral.

Formulación, elaboración, dirección y evaluación de proyectos turísticos y recreativos.

Coordinar equipos interdisciplinarios de planeamiento del desarrollo de los sectores turístico y recreativo.

Planificar, organizar, dirigir y controlar las actividades en áreas de competencia de nivel público y privado.

Ejercer funciones directivas de entes turísticos y recreativos, asesoramiento y asistencia técnica a esas funciones y a los cuadros operativos.

Realizar otros estudios y análisis vinculados a la estructura del turismo y al comportamiento de las actividades y servicios turísticos/recreativos.

Coordinar la toma de inventario, puesta en valor y determinación de acciones de preservación del patrimonio turístico y recreativo.

Organizar, coordinar y administrar instituciones prestadoras de servicios turísticos y recreativos.

Planificar y dirigir actividades recreativas destinadas tanto a grupos específicos como a la población en general.

Organizar y coordinar eventos singulares, tales como ferias, congresos y reuniones. (FACULTAD DE CIENCIAS ECONÓMICAS Y SOCIALES, OCA, n. 883, 2004, p. 4) 
Fuera de la Universidad se incrementa la oferta académica pública y privada con carreras en los distintos niveles y en las distintas especialidades, ampliándose la oferta de cursos de postgrado, maestrías en la modalidad presencial y a distancia.

Los Licenciados aceptan los cambios, se saben adaptar, demostrando que han alcanzado una inteligencia emocional, y logrado el famoso saber, hacer y ser y ponerlo en práctica.

En esta etapa la sociedad le asigna al Turismo un rol importante, los Licenciados en Turismo, ocupan cargos ejerciendo su profesión en organismos públicos oficiales y privados, en agencias de viajes, hotelería, parques temáticos, en transporte, en turismo accesible, en organismos ambientales, instituciones intermedias, otras empresas, institutos de investigaciones y centros de documentación.

Son los únicos capacitados en el conocimiento del fenómeno turístico y su interrelación con otras disciplinas.

La última etapa denominada "Aterrizaje"comienza con el segundo lustro del siglo XXI.

Es la que recibe a un profesional formado con los conocimientos y el logro del saber, ser y hacer para ocupar los roles que le competen por formación en los distintos puestos de trabajo.

El concepto de calidad se instaló en el mercado turístico y se construye aumentando las ventajas comparativas y competitivas basadas en una infraestructura informática y de comercialización sujetas a los vaivenes políticos nacionales e internacionales sometidos en algunos casos a las oscilaciones del cambio climático. Es la etapa donde los cambios en el mercado turístico se perfilan rápidos y continuados.

En los ámbitos periodísticos se denomina al turismo: "el motor silencioso de la economía", convirtiéndose en el sector con mayor impulso después de la devaluación del año 2001.

Hoy ocupa el cuarto lugar por ingreso de divisas en el país, atrás de las oleaginosas, petróleo y de la industria automotriz, estando por encima de los aportes que dan los cereales y la carne.

De la lectura del Anexo 1 de la Ley Nacional de Turismo y del Perfil Profesional se deduce que están formados en competencias acordes a las acciones de coordinación, 
planificación, gestión, organización, educación y administración de todas las actividades turísticas numeradas.

El texto de la Ley es claro: identifica las actividades turísticas y el perfil de egreso de graduado de la Universidad Nacional de Mar del Plata, las competencias, siendo coincidentes las dos propuestas.

Al determinar la Ley las Actividades del sector y la Universidad determinar las competencias, queda aclarado el campo ocupacional del licenciado en turismo y su inserción en el mercado laboral.

Esta lectura elimina las dudas que se producen con otras profesiones en el caso de las incumbencias profesionales.

Por lo tanto es hora que en el mercado laboral cada profesión ocupe el lugar de empleo para el cual estudió, y no que profesionales provenientes de disciplinas independientes vean en el turismo su modo de vida y ocupen puestos en educación, investigación, planificación o gestión para los cuales no han sido formados y que desde que se creó la Licenciatura en turismo lo han hecho y lo hacen.

Es en esta etapa donde el Licenciado en Turismo para afianzar su rol e instalarse en el conocimiento pleno de la comunidad tendrá que participar en la educación formal e informal, sólo en los temas que le competen.

En la educación formal secundaria y terciaria, dictando las cátedras específicas, participando de los diseños curriculares, organizando y dirigiendo cursos.

En la Educación informal ser los formadores en sensibilización turística, en la comunidad residente.

En el 2007 el buen trato en turismo es la base de la calidad. Para lograr ese objetivo trabajar creando conciencia turística basada en la hospitalidad es un proceso de años.

En el caso de la Universidad Nacional de Mar del Plata, se intensifica la investigación con el Centro de Investigaciones Turísticas, implementándose la ampliación del Centro de Documentación de la Facultad con un Área específica de Turismo, por intermedio de ayuda económica recibida de la Universidad de Islas Baleares. 
La Asociación de Licenciados en Turismo, presenta ante las autoridades parlamentarias de la Provincia de Buenos Aires el proyecto de ley de Reglamentación de las Actividades Profesionales y el proyecto de Colegiatura Profesional.

Licenciados en Turismo, ocupan cargos jerárquicos en Organismos Públicos de Turismo y en empresas privadas, locales nacionales y del exterior. En otros casos forman consultoras, son microemprendedores y prestan sus servicios en empresas del Tercer Sector, esto es un signo de un comienzo de aceptación y reconocimiento por parte de la comunidad.

Los Estudiantes de Turismo de las distintas universidades del país, refundan la ANET - Asociación Nacional de Estudiantes de Turismo, hecho significativo y esperanzado para el futuro de la profesión.

La Facultad de Ciencias Económicas y Sociales en su política de extensión ofrece a la comunidad regional cursos de Hospitalidad Turística y a escuelas de nivel primario cursos de Sensibilización Turística, dictado por profesionales en turismo.

\section{CONCLUSIÓN}

Evaluada la trayectoria de la formación del Licenciado en Turismo se arriba a la conclusión que su rol específico en la Argentina consiste en Concientizar a la comunidad en general de la problemáticas social, cultural, económica y política vinculadas a la actividad, preservando la herencia científico-cultural y promoviendo la creación de nuevos conocimientos que estén relacionados con la problemática local, nacional y regional.

Incentivar la investigación académica en temas importantes para la comunidad y que sean de aplicación real a la actividad turística.

Continuar formándose académicamente y transferir el conocimiento compartiendo ideas y reflexionando sobre los problemas que aquejan al sector discutiendo y buscando soluciones en forma conjunta.

Ejercer como profesionales un rol protagónico en el proyecto país y de la SECTUR - Secretaría de Turismo de la Nación; Subsecretaría de Turismo de la Provincia de Buenos Aires, y EMTUR - Ente Municipal de Turismo de Mar del Plata. 
Discutir y arribar a soluciones sobre la problemática de la profesión en Argentina y Mercosur, garantizando un turismo accesible para todas las personas.

Trabajar para mejorar la calidad de vida de la comunidad residente y turística.

Defender su espacio laboral, ganado por derecho de formación y ser remunerado con honorarios dignos, acorde a su título, responsabilidad y trabajo.

Hoy el mundo cambia día a día, hay nuevas problemáticas y profesionales que se forman para abordarlas en su totalidad, la Licenciatura en Turismo, forma la lista de las nuevas profesiones.

\section{REFERENCIAS}

Facultad de Ciencias Económicas y Sociales. 2004. OCA n. 883/04.ORDENANZA DE CONSEJO ACADÉMICO.

INDEC. Instituto Nacional de Estadísticas y Censo. Ministerio de Economía. Argentina 2007.

Secretaria de Turismo de la Nación. 2004. Ley 25.997/04. Argentina.

“Código Ético Mundial para el Turismo, 1999”. Secretaría de Turismo de la Nación. Normativa Vigente que rige la Actividad Turística. Compilación. Argentina. 2004.

REBOLLO, Vera, José y otros. "Análisis territorial del Turismo. Una nueva Geografía del Turismo". España.1997

Recebido em: 08 de agosto de 2007

Aprovado em: 08 de setembro de 2007 